\section{RSP}

http://www.rsp.fsp.usp.br/
Revista de Saúde Pública

\title{
Covid-19 and the pandemic of fear: reflections on mental health
}

\author{
Dandara Almeida Reis da Silva' \\ das Merces' iD \\ Universidade do Estado da Bahia. Departamento de Ciências da Vida. Salvador, BA, Brasil \\ " Universidade Federal da Bahia. Complexo Hospitalar Professor Edgard Santos. Salvador, BA, Brasil
}

Covid-19 is a respiratory infection caused by coronavirus- initially detected in China, in December 2019, which progresses to pneumonia in $81 \%$ of the cases, with an average fatality rate of $2.3 \%^{1}$. It was declared a pandemic by the World Health Organization on March 11,2020, almost ninety days after the first cases appeared. With high transmissibility, vertiginous increase in the number of cases, and clinical severity, it is impossible to disregard its psychological effects.

Despite being a recent pathology, studies addressing the theme of emotional stress in today's scenario already emerged. The bibliographic research conducted on March 22, 2020, using the search strategies "Psychological Stress AND covid 19", "Estresse Psicológico AND covid 19", and "mental disorder AND covid 19" in Pubmed and BIREME, found seven articles, all with equivalence in both databases. No other filters have been defined. Two articles in Chinese were not evaluated. After reading the other five articles in full, two were originals; the others represented brief communications.

Both original articles with primary data were conducted in China. One of these papers evaluated three groups: general population, frontline nurses and general nurses ${ }^{2}$. Frontline nurses were the least affected by emotional stress, condition linked to strategies to cope with emotional stress developed by these professionals. However, the accumulation of work overload may change this scenario, and the continuous exposure to emotional stress may trigger other disorders ${ }^{3}$. Regardless of the group, emotional stress was present in more than $60 \%^{2}$. In the general population (1210 individuals), $28.8 \%$ exhibited symptoms of moderate to severe anxiety and $53.8 \%$ reported psychological impact of moderate to severe intensity, because of the epidemic ${ }^{4}$.

Considering the epidemiological behavior of covid-19, the period of social isolation may be necessary indefinitely. Regardless of the covid-19 pandemic, social isolation itself is capable of triggering psychotic symptoms, as Kellerman et al. described in $1977^{5}$. In this study, they evaluated individuals in social isolation due to oncological disease, and observed symptoms of depression (92.3\%), anxiety (76.9\%), sleep disorders (61.5\%) and hallucinations in 38.5\% of the subjects, among other alterations 5 .

Besides the covid-19 pandemic, health professionals and the general population are at risk of mental illness. We must develop psychological support strategies to promote mental health, emphasizing the use of online technologies to maintain the necessary physical distancing. Keep in mind those already suffering from psychiatric disorders, which can be worsened by the current scenario. Surveillance will be needed to control the "pandemic of fear" and treat mental illness even after the covid-19 pandemic is resolved. 


\section{REFERENCES}

1. Wu Z, McGoogan JM. Characteristics of and important lessons from the Coronavirus Disease 2019 (COVID-19) outbreak in China: summary of a report of 72314 cases from the Chinese Center for Disease Control and Prevention]. JAMA. 2020;323(13):1239-42. https://doi.org/10.1001/jama.2020.2648

2. Li Z, Ge J, Yang M, Feng J, Qiao M, Jiang R, et al. Vicarious traumatization in the general public, members, and non-members of medical teams aiding in COVID-19 control [published online ahead of print, 2020 Mar 10]. Brain Behav Immun. 2020. https://doi.org/10.1016/j.bbi.2020.03.007

3. Merces MC, Coelho JMF, Lua I, Silva DS, Gomes AMT, Erdmann AL, et al. Prevalence and factors associated with Burnout Syndrome among Primary Health Care nursing professionals: a cross-sectional study. Int J Environ Res Public Health. 2020;17(2):474. https://doi.org/10.3390/ijerph17020474

4. Wang C, Pan R, Wan X, Tan Y, Xu L, Ho CS, et al. Immediate psychological responses and associated factors during the initial stage of the 2019 Coronavirus Disease (COVID-19) epidemic among the general population in China. Int J Environ Res Public Health. 2020;17(5):1729. https://doi.org/10.3390/ijerph17051729

5. Kellerman J, Rigler D, Siegel SE. The psychological effects of isolation in protected environments. Am J Psychiatry. 1977;134(5):563-5. https://doi.org/10.1176/ajp.134.5.563

Authors' Contributions: Study design and planning: DARS, RFWP, MCM. Data collection, analysis and interpretation: DARS, RFWP, MCM. Manuscript development: DARS, RFWP, MCM. Critical review: DARS, MCM. Approval of the final version: DARS, MCM.

Conflict of interest: The authors declare no conflict of interest. 